\title{
Fuzzy Logic Systems for Diagnosis of Renal Cancer
}

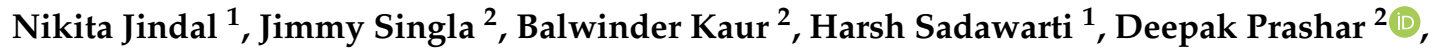 \\ Sudan Jha ${ }^{2}$, Gyanendra Prasad Joshi ${ }^{3, *}{ }^{-1}$ and Changho Seo ${ }^{4, *}$ \\ 1 School of Engineering and Technology, CT University, Punjab 142024, India; \\ nikita.jindal17@gmail.com (N.J.); sadawartiharsh@gmail.com (H.S.) \\ 2 School of Computer Science and Engineering, Lovely Professional University, Punjab 144411, India; \\ jimmy.21733@lpu.co.in (J.S.); balwinder.kaur0315@gmail.com (B.K.); Deepak.prashar@lpu.co.in (D.P.); \\ jhasudan@hotmail.com (S.J.) \\ 3 Department of Computer Science and Engineering, Sejong University, Seoul 05006, Korea \\ 4 Department of Convergence Science, Kongju National University, Gongju 32588, Korea \\ * Correspondence: joshi@sejong.ac.kr (G.P.J.); chseo@kongju.ac.kr (C.S.); \\ Tel.: +82-2-69352481 (G.P.J.); +82-10-8826-7179 (C.S.)
}

Received: 16 March 2020; Accepted: 14 May 2020; Published: 17 May 2020

check for updates

Featured Application: The proposed intelligent medical system is applicable for a medical diagnostic system, especially for diagnosis of renal cancer.

\begin{abstract}
Renal cancer is a serious and common type of cancer affecting old ages. The growth of such type of cancer can be stopped by detecting it before it reaches advanced or end-stage. Hence, renal cancer must be identified and diagnosed in the initial stages. In this research paper, an intelligent medical diagnostic system to diagnose renal cancer is developed by using fuzzy and neuro-fuzzy techniques. Essentially, for a fuzzy inference system, two layers are used. The first layer gives the output about whether the patient is having renal cancer or not. Similarly, the second layer detects the current stage of suffering patients. While in the development of a medical diagnostic system by using a neuro-fuzzy technique, the Gaussian membership functions are used for all the input variables considered for the diagnosis. In this paper, the comparison between the performance of developed systems has been done by taking some suitable parameters. The results obtained from this comparison study show that the intelligent medical system developed by using a neuro-fuzzy model gives the more precise and accurate results than existing systems.
\end{abstract}

Keywords: renal cancer; diagnosis; fuzzy logic; neuro-fuzzy technique

\section{Introduction}

Renal cancer occurs when the cells in the kidney grow even if the body does not need that growth of cells [1]. These cells that are abnormal will form a mass and this is known as a tumor [2]. If these lumps are in a body for a long time period, then it can affect neighbor organs or areas and can expand or spread to other parts of that particular body. This cancer of renal is called renal cell cancer $[3,4]$. Adults are often suffering from this cancer [5]. As the kidney is the main organ of the body to filter the body's blood and to excrete the waste material in the body, it is very crucial to diagnose renal cancer at the right time [6]. There is no sign or symptoms to detect this cancer at early stages [7]. Additionally, there is no test available in the medical that detects it without any sign.

The main reason for this cancer is smoking [8]. Hence, it is observed that men have more risk of renal cancer than women [9,10]. It can occur due to hereditary or genetic symptoms [11]. According to the observations, 3 to 5 percent of patients fight with renal cancer due to their family background. There are 12 different genes that cause cancer in the kidney due to inheritance [12]. This cancer may 
also re-occur after a number of years has passed after diagnosis [12]. Therefore, it is essential to take care of a patient of renal cancer even after diagnosis and treatment. Regular check-ups should be there so that the risk of re-occurrence of renal cancer will be decreased.

There are a number of techniques used for the detection and diagnosis of renal cancer. The often-used technique by researchers is image processing [13,14]. Various image processing techniques have been applied on the image of the kidney to identify the biomarkers and stage of renal cancer [15]. The classification has been done according to the features extracted from the acquired picture of the kidney of a particular patient $[16,17]$. There are also many tools developed by researchers to identify and monitor the growth of a tumor $[17,18]$.

The input variables that help medical intelligent system to diagnose the renal cancer [1] are as follows:

- Haematuria

- Red blood cell count

- Flank pain

- Tumor size

- Von Hippel-Lindau syndrome

- High blood pressure

- Trichloroethylene exposure

\subsection{Artificial Neural Network}

The artificial neural network is a model which is trained to do a particular task as the brain of the human can do. It is essentially a simulation of the human brain. It can do various tasks or operations in a distributed and parallel manner. The neuron in this network helps to complete complex and sophisticated jobs in less time. There are many types of neural networks that are used to resolve any problems. The main applications of an artificial neural network are in the medical field, agriculture and many more domains [19].

The flow of doing work by the neural network is the input given to the neurons of an input layer. These inputs are combined with the weights given to every link between the input layer to the next layer. There is an external force fed to the network, known as bias. All the inputs, weights and given bias are summed up with each other by the function known as summation function. An activation function is also used which gives the final output generated by the neural network [20]. The basic model of the artificial neural network is illustrated in Figure 1.

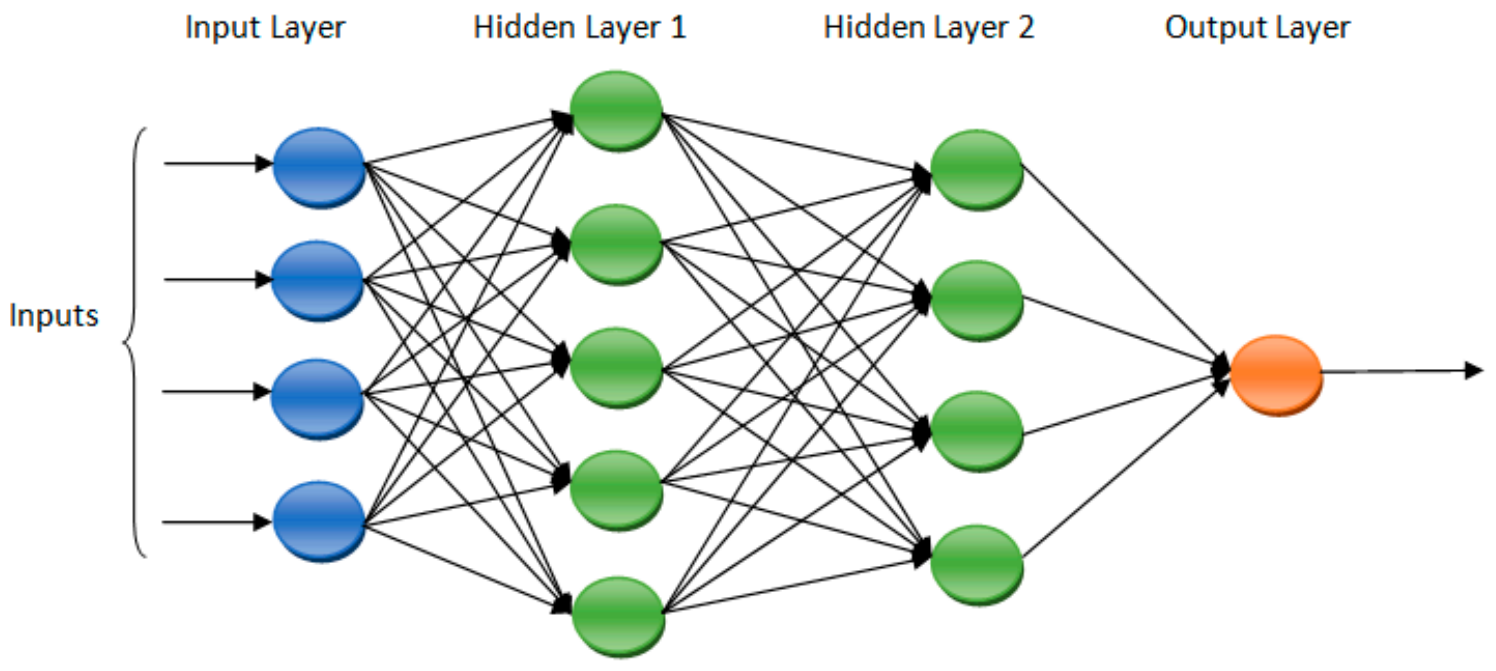

Figure 1. Artificial neural network. 


\subsection{Fuzzy Inference System}

The fuzzy inference system deals with imprecise and fuzzy data. It calculates the output by using fuzzy logic. Fuzzy logic will return output between the range of 0 to 1 [21]. Principally, it is used in the development of expert systems for classification and makes the decision on it as the human brain does. The decision depends on the rules stored in the knowledge base of the inference system. The rules are in the IF-THEN manner [22].

There are four main elements used in the fuzzy inference system. These elements are given below:

- Fuzzifier: It transforms given inputs into fuzzy values.

- Fuzzy Knowledge Base: Facts and rules are stored into the knowledge base

- Inference Engine: It maps the rules corresponding to fed inputs and gives results.

- Defuzzifier: It transforms the result of the inference engine into crisp values.

These elements are combined with each other, as elaborated in Figure 2.

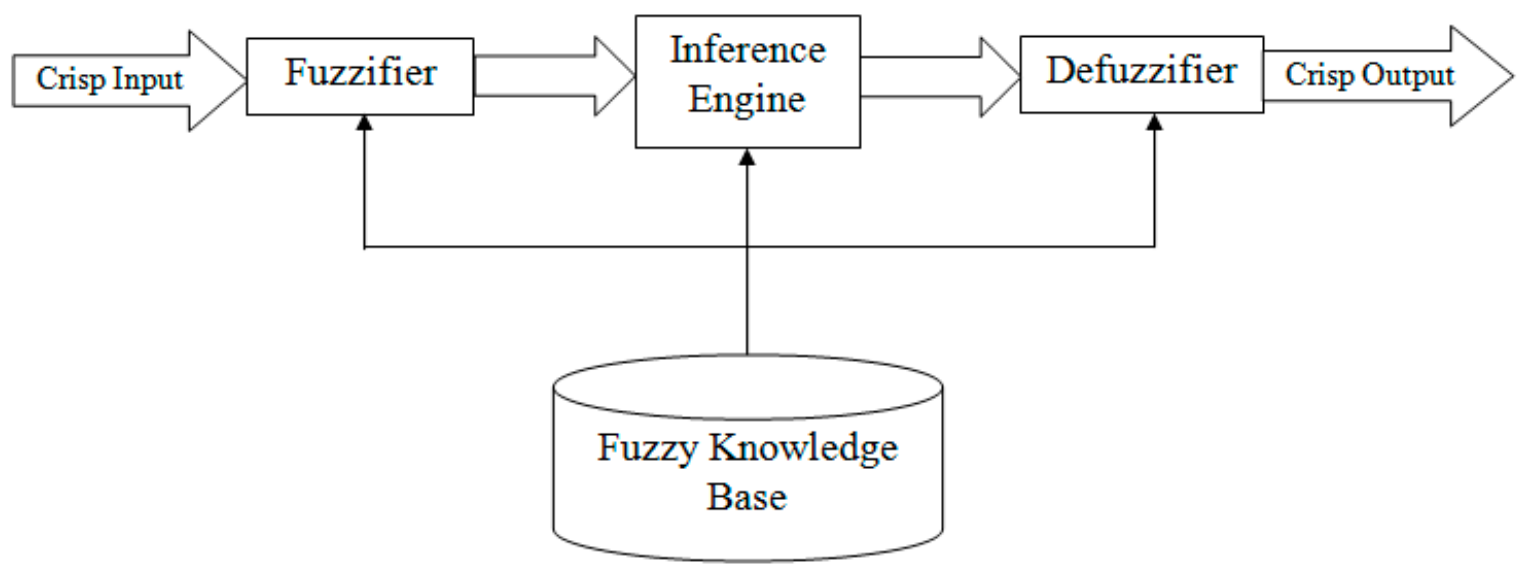

Figure 2. Architecture of the Fuzzy inference system.

\subsection{Adaptive Neuro-Fuzzy Inference System (ANFIS)}

An adaptive neuro-fuzzy inference system is a type of neural network which is based on the fuzzy inference system [23]. The Sugeno fuzzy inference system is used in ANFIS [2]. It is basically used in the identification of parameters. It is a hybrid system that combines the back propagation and LMS method to calculate the error [24]. This system merges the capabilities of a neural network with fuzzy logic to solve the problems $[25,26]$. It automatically generates rules and linguistic values of membership function during the training phase. The rules are constructed in the form of IF-THEN. The synaptic weights are not used in this system. The error is calculated by doing the differences between the target value and the observed value from the trained system. The developed ANFIS is able to give accurate results for unseen data also. This is evaluated in the testing phase of the developed system. This leads to better performance of the system as compared to other systems. There are five layers in the ANFIS [16]. These layers are as follows:

- Fuzzification Layer

- Rule Layer

- Normalization Layer or membership function layer

- Defuzzification Layer

- Summation Layer.

The structure of an adaptive neuro-fuzzy inference system is given in Figure 3. 


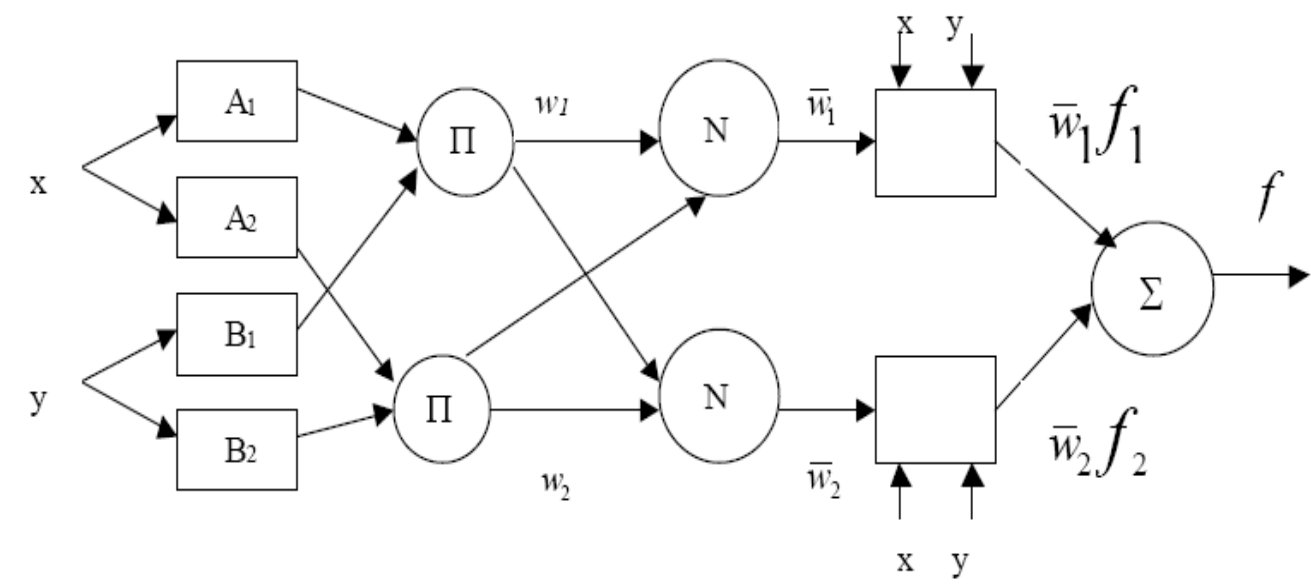

Figure 3. Structure of five-layer ANFIS.

The five layers of the adaptive neuro-fuzzy inference system have been described below.

Layer 1: In the first layer of ANFIS, each node adjusts a function parameter. The value of membership function is put forward as the output by each node of this layer as mentioned below:

$$
O_{1, i}=u_{A_{i}}(x) \text {, where } i=1,2 O_{1, i}=u_{B i-2}(x) \text {, where } i=3,4
$$

where $u_{A_{i}}$ and $u_{B i-2}=$ degree of membership function for $A_{i}$ and $B_{i}$, and here, $A_{i}$ and $B_{i}$ are fuzzy sets.

Layer 2: The nodes present in this layer are fixed. These nodes represent the firing strength of each rule. The outcome for this layer is the multiplication of signals coming into the node and carry out to the next node as follows:

$$
O_{2, i}=w_{i}=\mu_{A i}(x) \times \mu_{B i}(y), \text { where } i=1,2
$$

where $w_{i}=$ firing strength of each rule.

Layer 3: In layer 3, the nodes present in it are also fixed. The output of this layer is calculated by dividing the firing strength of $\mathrm{i}^{\text {th }}$ rule by the total sum of firing strength of all rules. The output of this layer is known as the normalized firing strength.

$$
O_{3, i}=\bar{w}_{i}=\frac{w_{i}}{\sum_{i} w_{i}}
$$

Layer 4: The nodes present in the layer 4 are adaptive nodes to an outcome. The node function for this later is defined as follows:

$$
O_{4,1}=\bar{w}_{i} f_{i}=w_{i}\left(p_{i} x+q_{i} y+r_{i}\right)
$$

where $\bar{w}_{i}=$ Normalized firing strength calculated at layer 3 and $\left(p_{i} x+q_{i} y+r_{i}\right)=$ parameters in the nodes.

Layer 5: This is the last layer of ANFIS and has only one fixed node. The output of this layer can be calculated by taking the summation of all the incoming signals from the previous node. The outcome of this layer is the final output of the system.

$$
O_{5, i}=\sum_{i} \bar{w}_{i} f_{i}=\frac{\sum_{i} w_{i} f_{i}}{\sum_{i} w_{i}}
$$

\section{Dataset and Method for Fuzzy Inference System}

Figure 4 depicts the methodology that is used in the proposed multi-layered system for the recognition of renal cancer. 


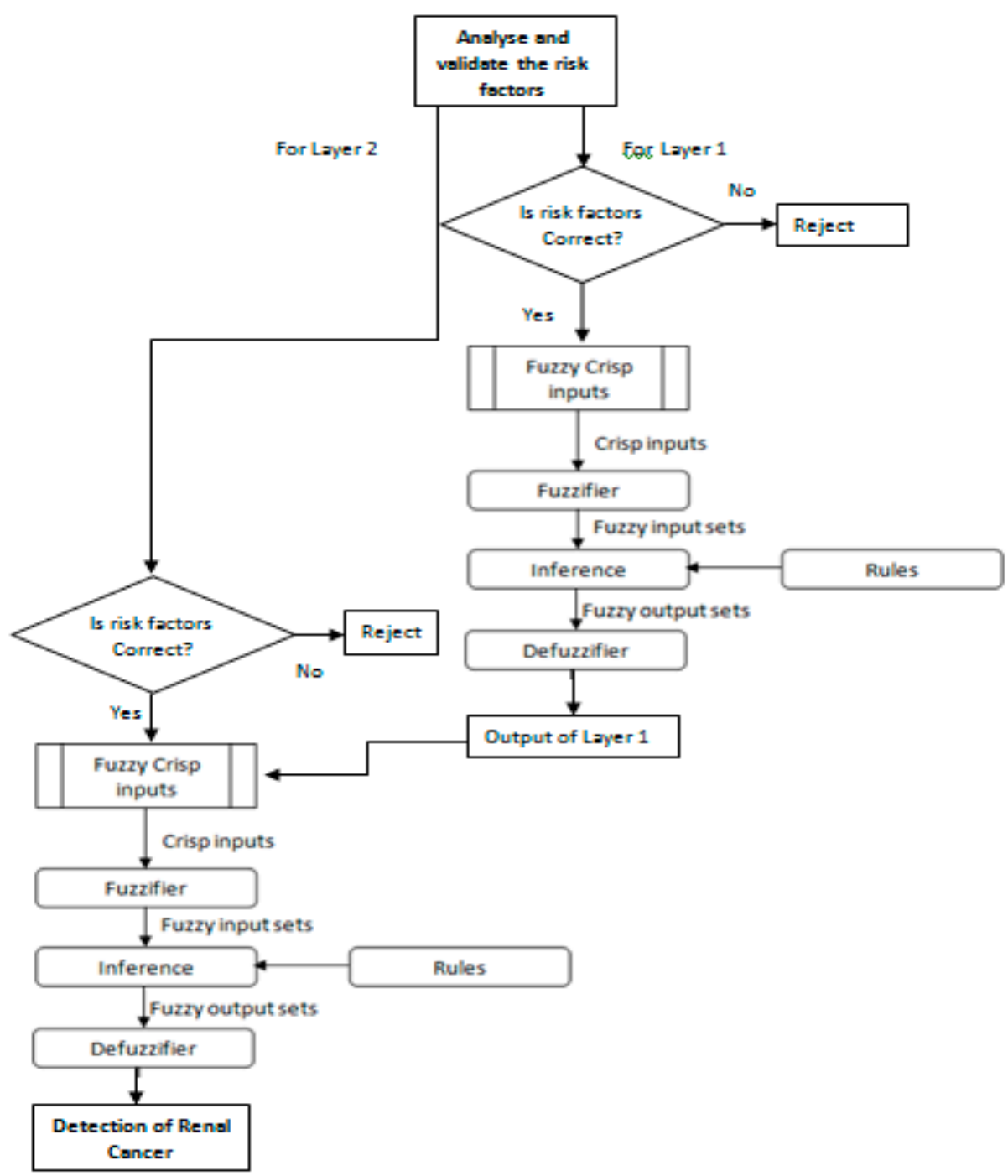

Figure 4. Methodology of the proposed multi-layered inference system.

MATLAB software is used for the development of this proposed system by using the Mamdani fuzzy model of fuzzy logic. The inputs used for the first layer are smoking, dialysis, occupational exposure (OE), genetic or hereditary (GOR). Similarly, for the second layer, the used inputs are blood in urine, red blood cell count, flank pain, tumor size, Von Hippel-Lindau gene, high blood pressure, and trichloroethylene exposure.

Tables 1-3 show the values used for the input variables at layer 1, at layer 2 and for the output variables, respectively. 
Table 1. Input variables used in layer 1 of the proposed system.

\begin{tabular}{cccc}
\hline SNo & Input Parameters & Ranges & Semantic Sign \\
\hline \multirow{2}{*}{1} & \multirow{2}{*}{ Smoking } & $<4.3$ & Acute \\
& & {$[0.2,9]$} & Moderate \\
& $>5.8$ & Chronic \\
\hline \multirow{2}{*}{2} & \multirow{2}{*}{ Dialysis } & $<4.5$ & No \\
& & $>1.9$ & Yes \\
\hline \multirow{2}{*}{3} & \multirow{2}{*}{ OE } & $<4.5$ & Little Bit \\
& & $>1.9$ & Excessive \\
\hline \multirow{2}{*}{4} & \multirow{2}{*}{ GOH } & $<4.4$ & Low \\
& & {$[0.5,9.2]$} & Moderate \\
& & $>5.8$ & High \\
\hline
\end{tabular}

Table 2. Input variables used in layer 2 of the proposed system.

\begin{tabular}{cccc}
\hline SNo & Input Parameters & Ranges & Semantic Sign \\
\hline 1. & & $<27$ & $1+$ \\
& & {$[10,50]$} & $2+$ \\
& & {$[15,85]$} & $3+$ \\
& $>55$ & $4+$ \\
\hline 2. & RBCC & $<0.45$ & Low \\
& & {$[0.05,0.95]$} & Normal \\
& & $>0.58$ & High \\
\hline 3. & FP & $<0.48$ & Low \\
& & {$[0.05,0.95]$} & Medium \\
& & $>0.52$ & High \\
\hline 4. & TS & $<7.2$ & Smaller \\
& & $>4.5$ & Larger \\
\hline 5. & VHLG & $<0.51$ & No \\
& & $>0.17$ & Yes \\
\hline 6. & HBP & $<96$ & Normal \\
& & $>76$ & High \\
\hline 7. & TCEE & $<5.5$ & Low \\
& & {$[1.6,9.3]$} & Moderate \\
& & $>6.2$ & High \\
\hline
\end{tabular}

Table 3. Output variables.

\begin{tabular}{cccc}
\hline SNo & & $\begin{array}{c}\text { Output } \\
\text { Variables }\end{array}$ & Semantic Sign \\
\hline $\mathbf{1 .}$ & Layer 1 & Renal Cancer & $\begin{array}{c}\text { Cancer Present } \\
\text { No Cancer }\end{array}$ \\
\hline $\mathbf{2 .}$ & Layer 2 & Cancer Stage & Minor \\
& & Moderate \\
& & Serious \\
& & Critical \\
\hline
\end{tabular}

Tables 4-6 show various statistical parameters, such as mean, standard deviation and frequency of the input variables of layer 1, input variables of layer 2 and output variables of both layers, respectively. 
Table 4. Parameter of layer 1.

\begin{tabular}{cccccc}
\hline SNo & Input Variables & $\begin{array}{c}\text { Linguistic } \\
\text { Variables }\end{array}$ & Mean & $\begin{array}{c}\text { Standard } \\
\text { Deviation }(\boldsymbol{\sigma})\end{array}$ & Frequency (f) \\
\hline \multirow{2}{*}{1.} & Smoking & Acute & 2.43 & 1.07 & 115 \\
& & Moderate & 4.88 & 0.60 & 67 \\
& Chronic & 7.44 & 1.28 & 18 \\
\hline 2. & Dialysis & No & 2.17 & 1.02 & 144 \\
& & Yes & 7.40 & 1.41 & 56 \\
\hline \multirow{2}{*}{3.} & \multirow{2}{*}{ Occupational Exposure } & Little Bit & 2.58 & 1.22 & 147 \\
& & Excessive & 7.56 & 1.50 & 53 \\
\hline \multirow{2}{*}{4.} & \multirow{2}{*}{ Genetic or hereditary } & Low & 2.45 & 1.36 & 102 \\
& & Moderate & 5.19 & 0.50 & 44 \\
& & High & 8.33 & 0.78 & 54 \\
\hline
\end{tabular}

Table 5. Parameters of Layer 2.

\begin{tabular}{|c|c|c|c|c|c|}
\hline SNo & Input Variables & $\begin{array}{l}\text { Linguistic } \\
\text { Variables }\end{array}$ & Mean & $\begin{array}{c}\text { Standard } \\
\text { Deviation }(\sigma)\end{array}$ & Frequency (f) \\
\hline \multirow[t]{4}{*}{1.} & Haematuria & $1+$ & 12 & 6.81 & 65 \\
\hline & & $2+$ & 41.70 & 6.15 & 72 \\
\hline & & $3+$ & 64.17 & 10.26 & 38 \\
\hline & & $4+$ & 137.53 & 59.17 & 25 \\
\hline \multirow[t]{3}{*}{2.} & Red blood cell count & Low & 0.25 & 0.07 & 81 \\
\hline & & Normal & 0.45 & 0.07 & 64 \\
\hline & & High & 0.65 & 0.13 & 55 \\
\hline \multirow[t]{3}{*}{3.} & Flank Pain & Low & 0.22 & 0.07 & 96 \\
\hline & & Medium & 0.40 & 0.09 & 89 \\
\hline & & High & 0.76 & 0.08 & 15 \\
\hline \multirow[t]{2}{*}{4.} & Tumor Size & Smaller & 5.50 & 1.57 & 162 \\
\hline & & Larger & 8.24 & 0.71 & 38 \\
\hline \multirow[t]{2}{*}{5.} & $\begin{array}{l}\text { Von Hippel-Lindau } \\
\text { syndrome }\end{array}$ & No & 0.30 & 0.05 & 147 \\
\hline & & Yes & 0.60 & 0.12 & 53 \\
\hline \multirow[t]{2}{*}{6.} & High Blood Pressure & Normal & 73.34 & 4.78 & 75 \\
\hline & & High & 92.88 & 15.09 & 125 \\
\hline \multirow[t]{3}{*}{7.} & $\begin{array}{l}\text { Trichloroethylene } \\
\text { Fxposure }\end{array}$ & Low & 2.554 & 0.39 & 10 \\
\hline & & Moderate & 4.01 & 0.82 & 97 \\
\hline & & High & 7.71 & 1.07 & 93 \\
\hline
\end{tabular}

Table 6. Parameters of outputs.

\begin{tabular}{ccccccc}
\hline SNo & Layer & $\begin{array}{c}\text { Output } \\
\text { Variables }\end{array}$ & $\begin{array}{c}\text { Linguistic } \\
\text { Variables }\end{array}$ & Mean & $\begin{array}{c}\text { Standard } \\
\text { Deviation }(\boldsymbol{\sigma})\end{array}$ & $\begin{array}{c}\text { Frequency } \\
(\mathbf{f})\end{array}$ \\
\hline \multirow{2}{*}{1.} & \multirow{2}{*}{ Layer 1} & \multirow{2}{*}{ Renal Cancer } & $\begin{array}{c}\text { Cancer } \\
\text { Present }\end{array}$ & 5.86 & 0.32 & 74 \\
& & & No Cancer & 2.12 & 1.52 & 126 \\
\hline \multirow{2}{*}{2.} & Layer 2 & \multirow{2}{*}{ Cancer Stage } & Minor & 2.07 & 0.21 & 68 \\
& & & Moderate & 5.10 & 0.79 & 85 \\
& & & Serious & 8.04 & 0.73 & 22 \\
& & & Critical & 8.67 & 0.11 & 25 \\
\hline
\end{tabular}




\subsection{Membership Functions}

Gaussian membership functions are used for the input and output variables in the development of a multi-layered inference system for the diagnosis of renal cancer. These membership functions show the values used for every variable. Figures 5 and 6 show the graphical representation of the membership function of smoking and haematuria respectively. Figure 7 portrays the representation of membership function used for output variables in layer 2 in the graphical form.

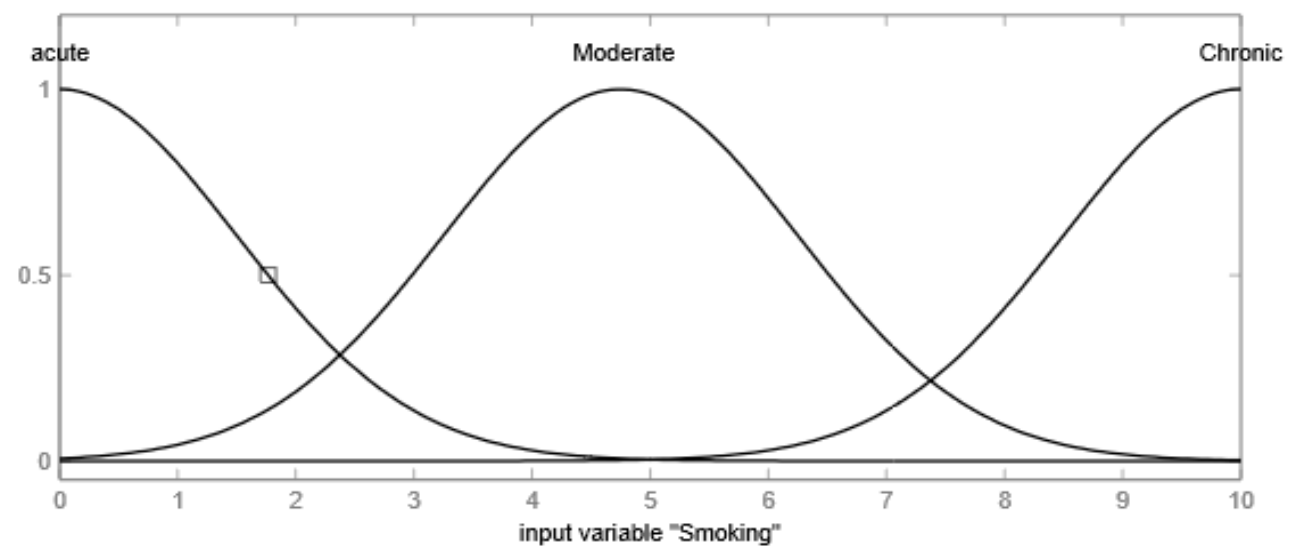

Figure 5. Membership Functions of input variable "Smoking".

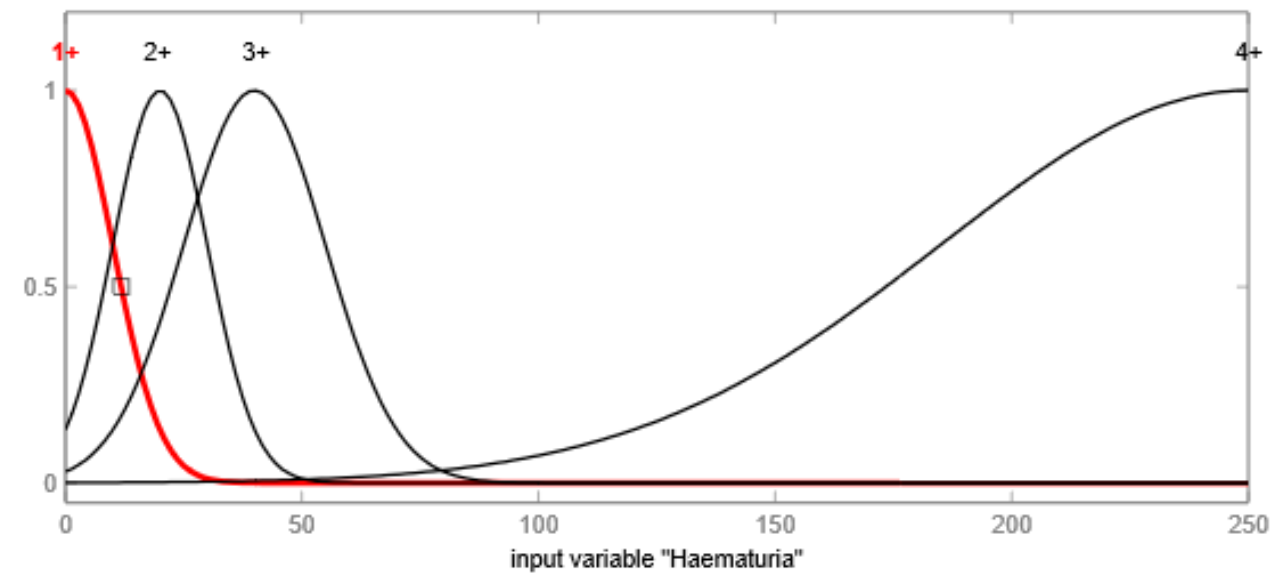

Figure 6. Membership Functions of input variable "Haematuria".

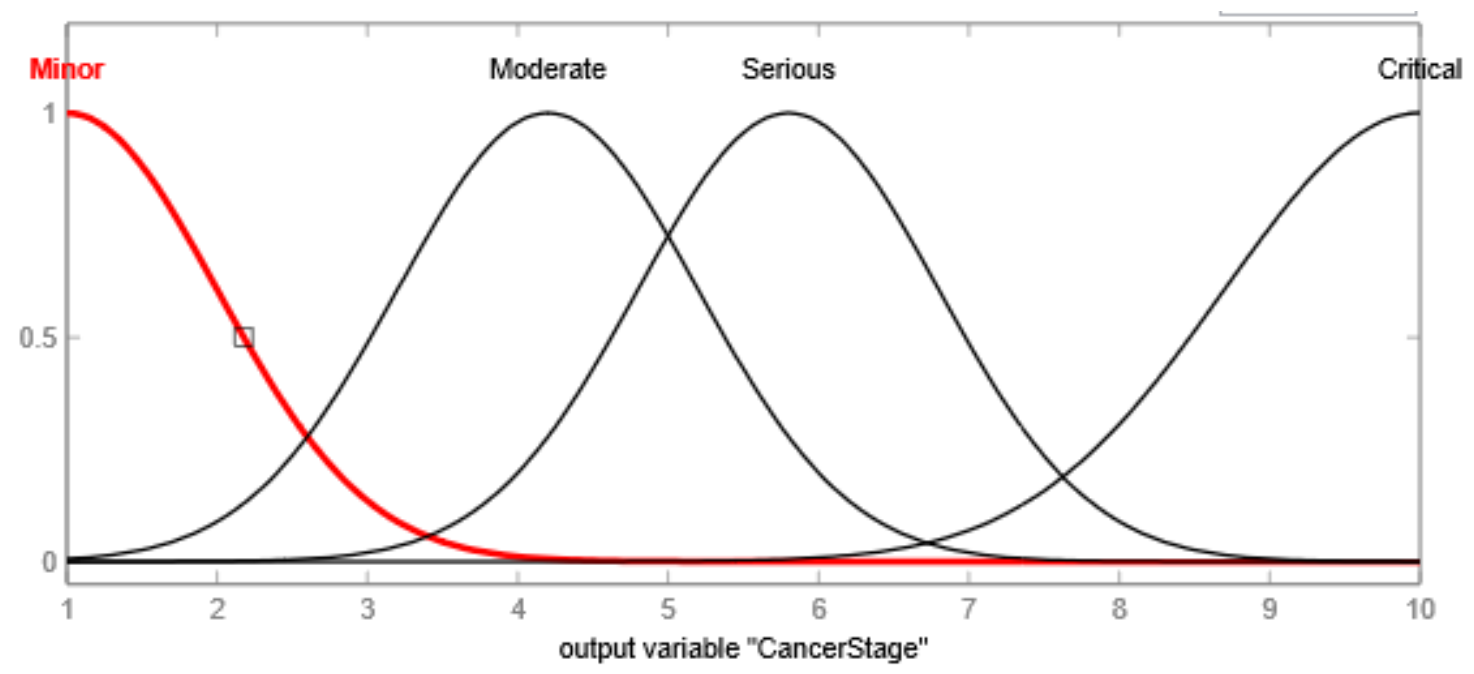

Figure 7. Membership function of output variable "Layer 2". 
The statistical values used for output variables as well as input variables for both layers can be represented in a mathematical function. The mathematical function of smoking is as shown as follows:

$$
\begin{aligned}
\mu_{\text {acute }}(x) & =e^{\frac{-(x-0)^{2}}{4.5}} \\
\mu_{\text {moderate }}(x) & =e^{\frac{-(x-4.47)^{2}}{4.5}} \\
\mu_{\text {chronic }}(x) & =e^{\frac{-(x-10)^{2}}{4.5}}
\end{aligned}
$$

\subsection{Rules}

A bundle of rules is stored in the knowledge base of the inference system according to the given inputs and expected outputs of the proposed system. The rules in the fuzzy inference system are aggregated by conjunction or disjunction and always in the IF-THEN form. Figure 8 shows the rules generated and stored in a knowledge base of the inference system for the diagnosis of renal cancer at layer 2. The rules are generated by multiplying the number of membership functions of each input variables are calculated as follows.

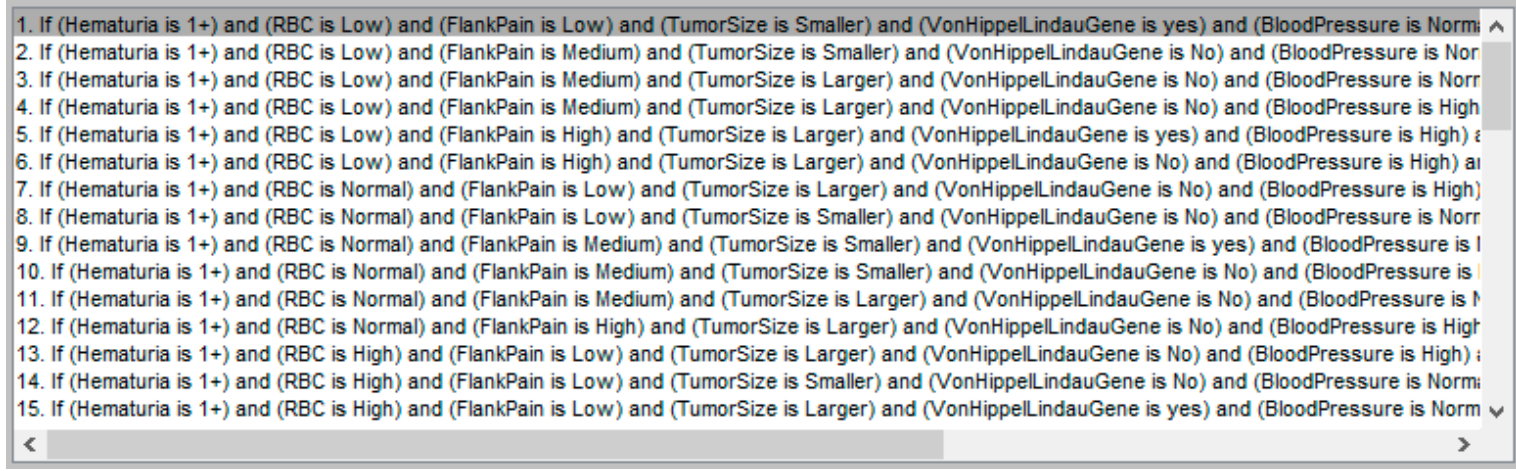

Figure 8. Rules used at layer 2 of proposed systems.

\section{For Layer 1,}

Total number of rules $=$ No. of membership functions of smoking $\times$ No. of membership functions of dialysis $\times$ No. of membership functions of occupational exposure $\times$ No. of membership functions of genetic or hereditary

$$
=3 \times 2 \times 2 \times 3=36 \text { rules }
$$

\section{For Layer 2,}

Total number of rules $=$ No. of membership functions of haematuria $\times$ No. of membership functions of RBCC $\times$ No. of membership functions of FP $\times$ No. of membership functions of TS $\times$ No. of membership functions of VHLG $\times$ No. of membership function of $\mathrm{HBP} \times$ No. of membership function of TCEE

$$
=4 \times 3 \times 3 \times 2 \times 2 \times 2 \times 3=864 \text { rules }
$$

\section{Dataset and Method for Adaptive Neuro-fuzzy Inference System}

The two well-known methods of soft computing are merged together to form a hybrid method known as a neuro-fuzzy method. This hybrid system is used for the development of an intelligent medical system to diagnose renal cancer. The input variables given to the medical diagnostic system are haematuria, red blood cell count, flank pain, tumor size, Von Hippel-Lindau gene, high blood pressure, and trichloroethylene exposure. Similarly, the output variables used in the proposed system are stages of renal cancer i.e., minor, moderate, serious and critical. The system is developed by using the methodology shown in Figure 9. 


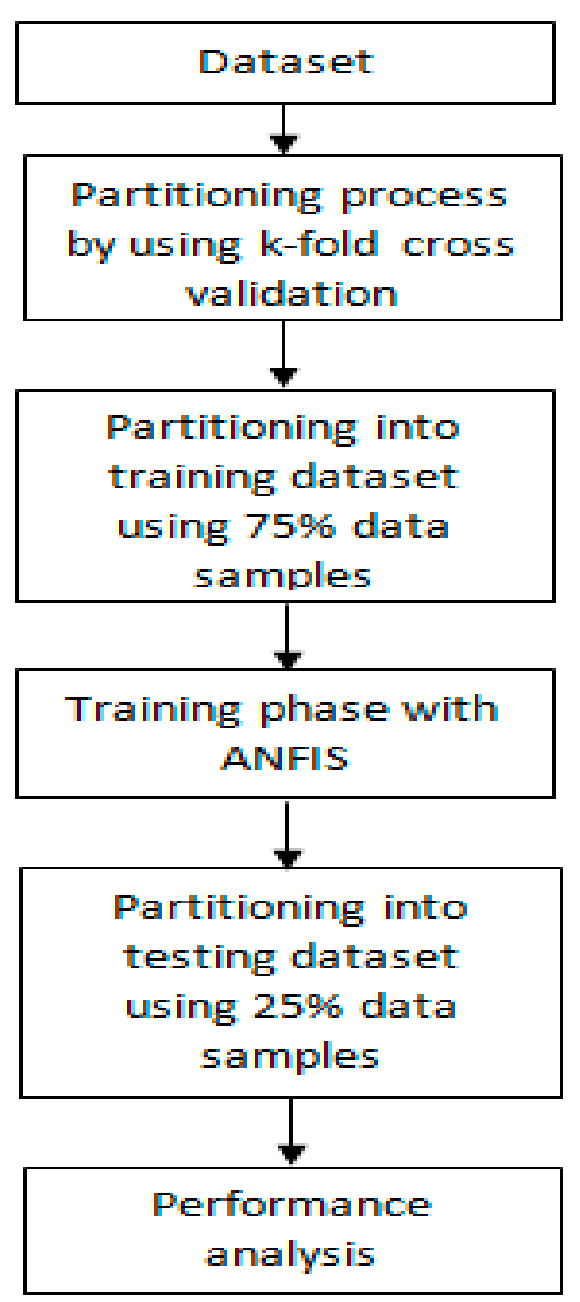

Figure 9. Flow diagram of developed intelligent system.

\subsection{Membership Function}

The Gaussian membership function is used for every input variable given to the system as well as for output variable. The number of Gaussian membership functions used is four for input1, three for input2, input3, and input7 and two for input4, input5 and input 6.

For example, for input variable tumor size, two groups are made according to a given range of variables. These are: smaller and larger. In the adaptive neuro-fuzzy technique, the groups of membership functions are automatically created by the system during the training phase of the proposed system. These groups are generated according to the given dataset for the training of a particular system. Figures 10-12 represent the graphical structure of membership functions of input1, input2, and input3, respectively. 


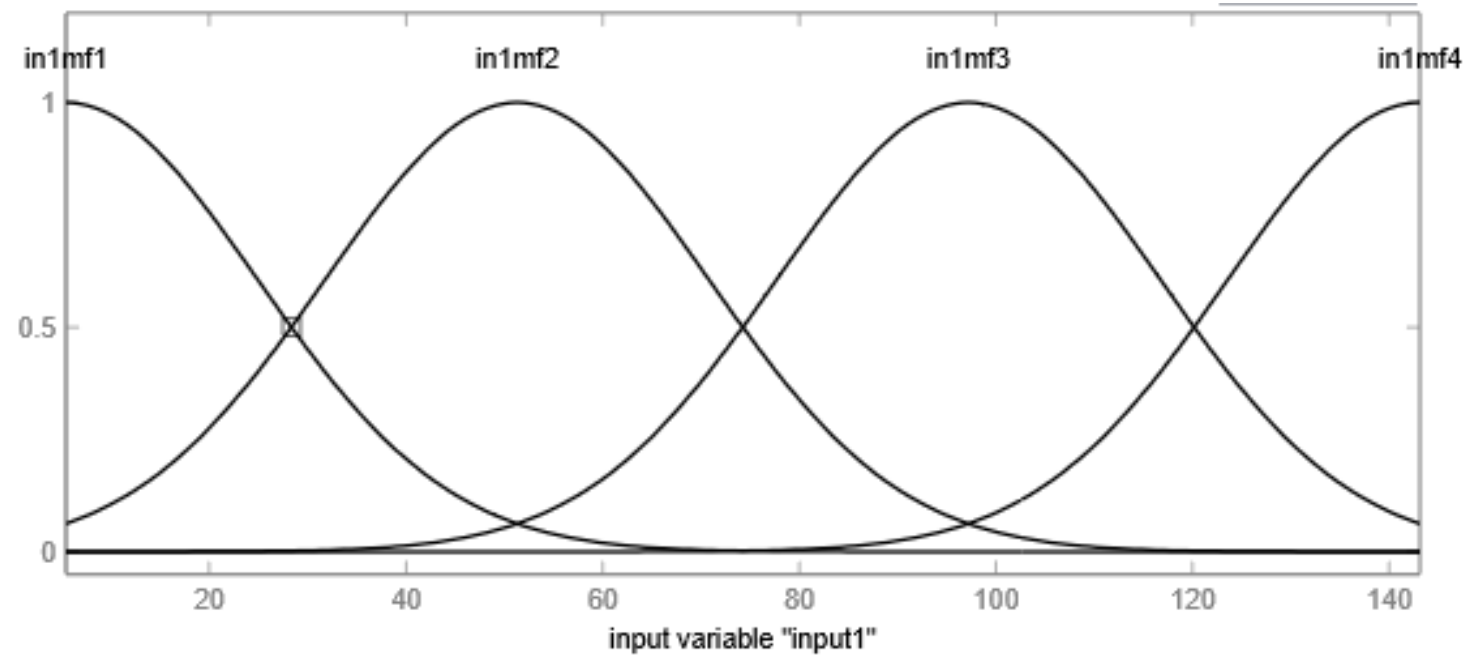

Figure 10. Membership function for input variable 1 i.e., Haematuria.

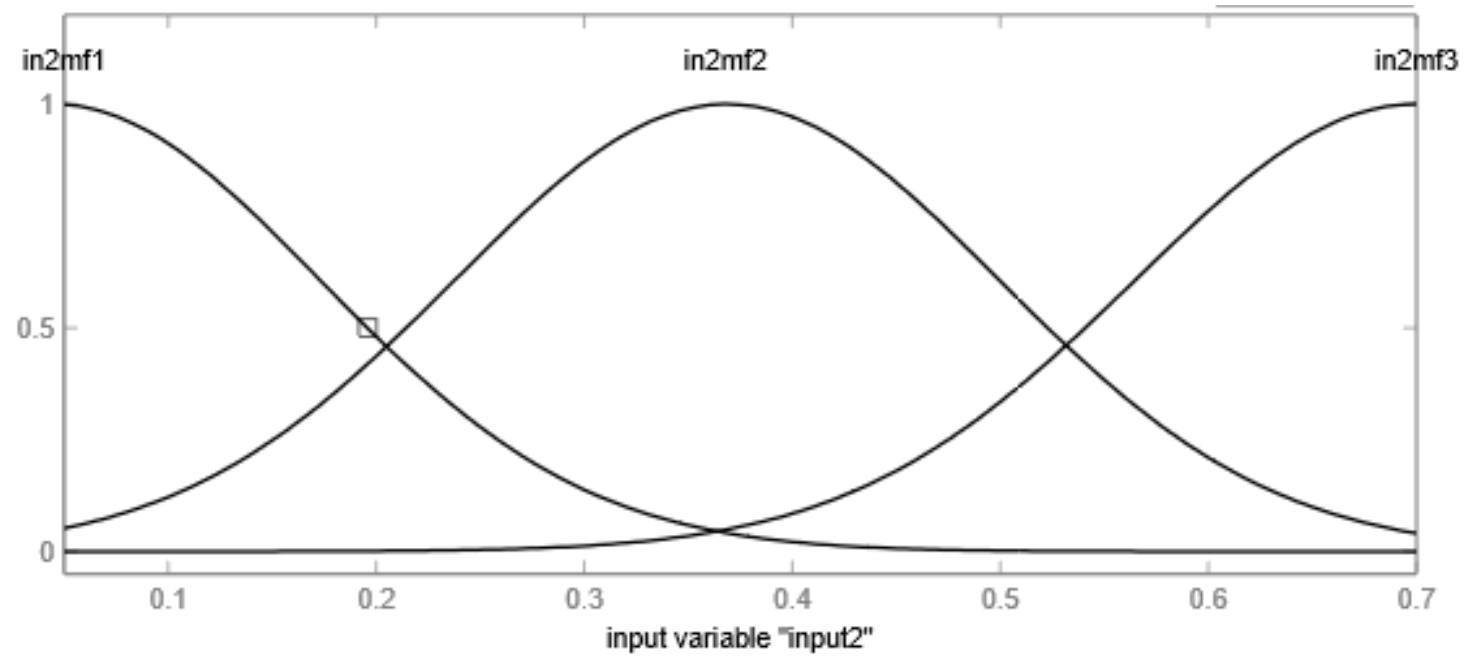

Figure 11. Membership function for input variable 2 i.e., RBCC.

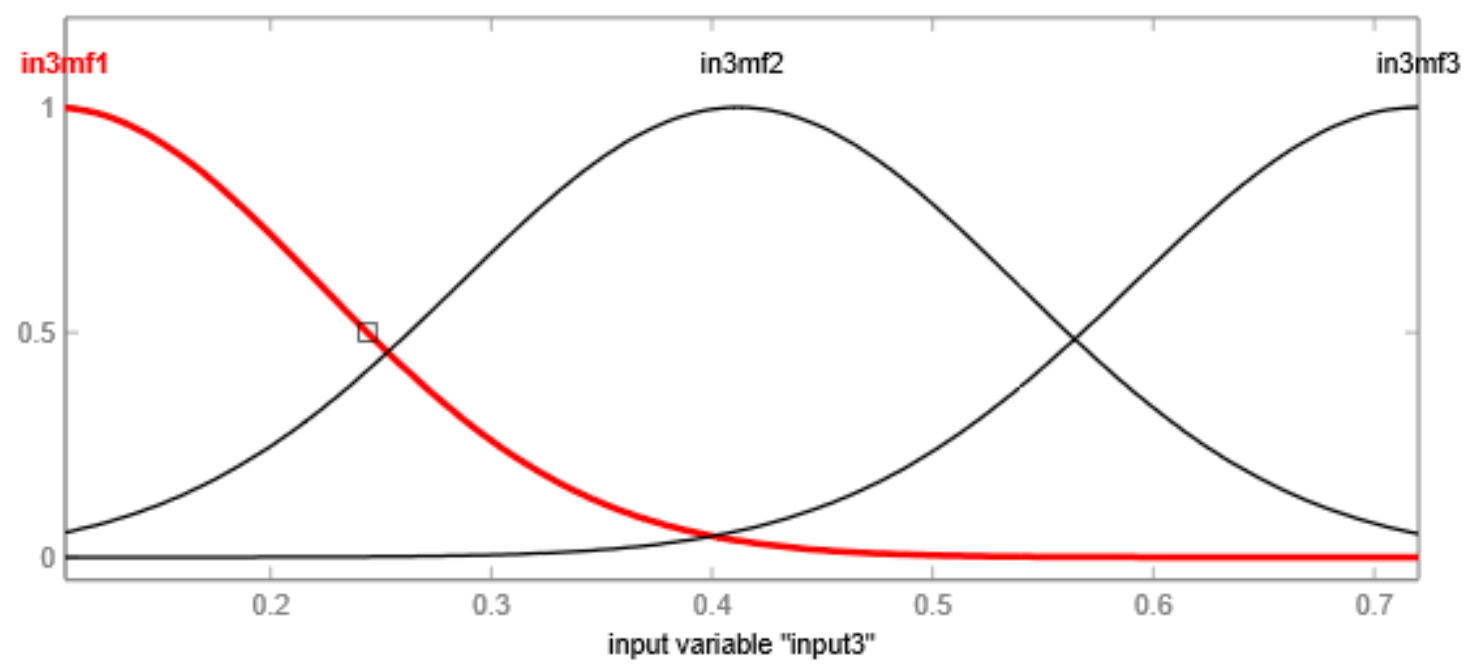

Figure 12. Membership function for input variable 3 i.e., Flank Pain. 
There are seven different input variables used for given inputs to the system that are from input 1 to input 7. Additionally, the output is used as a variable for output variables. Table 7 represents the structure of ANFIS for renal cancer.

Table 7. Structure of ANFIS for renal cancer.

\begin{tabular}{cc}
\hline \multicolumn{2}{c}{ Structure } \\
\hline The number of Layers of ANFIS \\
\hline Inputs & 7 \\
\hline Number of Rules & 864 \\
\hline Output & 1 \\
\hline Type of membership functions for input variables & Gaussian \\
\hline
\end{tabular}

\subsection{Rules}

The rules in this methodology are also generated automatically by the system during the training phase by taking all the possible mixtures of the given input variables to diagnose renal cancer. Figure 13 shows the rules generated by the system by using a training dataset. The total number of rules used in the proposed intelligent medical diagnostic system is 864 . The number of rules can be calculated by multiplying the number of membership functions used for every input variables of the system.

Therefore,

Total rules $=4 * 3 * 3 * 2 * 2 * 2 * 3=864$ rules.

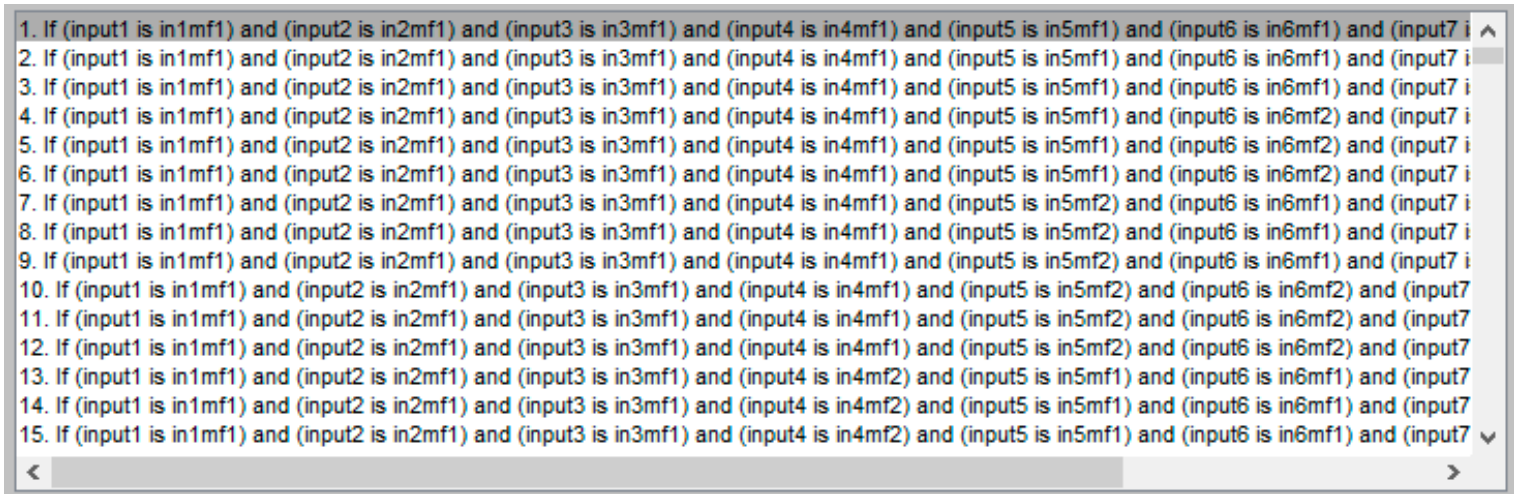

Figure 13. Rules in ANFIS for renal cancer.

\subsection{Training and Testing}

This phase of ANFIS is more essential in the development of a particular system. Initially, the dataset has been gathered from the experts of renal cancer. After that, the partitioning process has been done on an acquired dataset. This partitioning of the dataset has been done by using the k-fold cross validation. There are 200 different test cases in the acquired dataset.

For the cross-validation $\mathrm{k}=4$, the process is known as 4 -fold cross validation.

Hence, the dataset has been divided into four equal parts, from which three parts are used as training data and one part is used as testing data. In each iteration, the training and testing data has been changed according to the partitioning. It can be elaborated, like there are four parts of the dataset i.e., 1, 2, 3 and 4. For the first iteration, the first part is used as testing and the rest of the parts are used for training data. Similarly, in the second iteration, the second part of the dataset has been used to test the system and the rest of the parts, 1, 3 and 4, are used as the training data for the system and so on until the last iteration.

As there are 200 tests cases in the dataset, 150 test cases are used for the training data and 50 used for testing that particular system. Therefore, $75 \%$ of the data from the entire dataset has been used 
for the training phase of proposed system. The rest of the data $(25 \%)$ are used for the testing phase of a developed system as the testing data should be different from the training data. The number of epochs for training the system is 4 . The validation has been done to check whether the given system is able to classify the patients of renal cancer and non-renal cancer in a correct class or not. The training error after the training phase is shown in Figure 14.

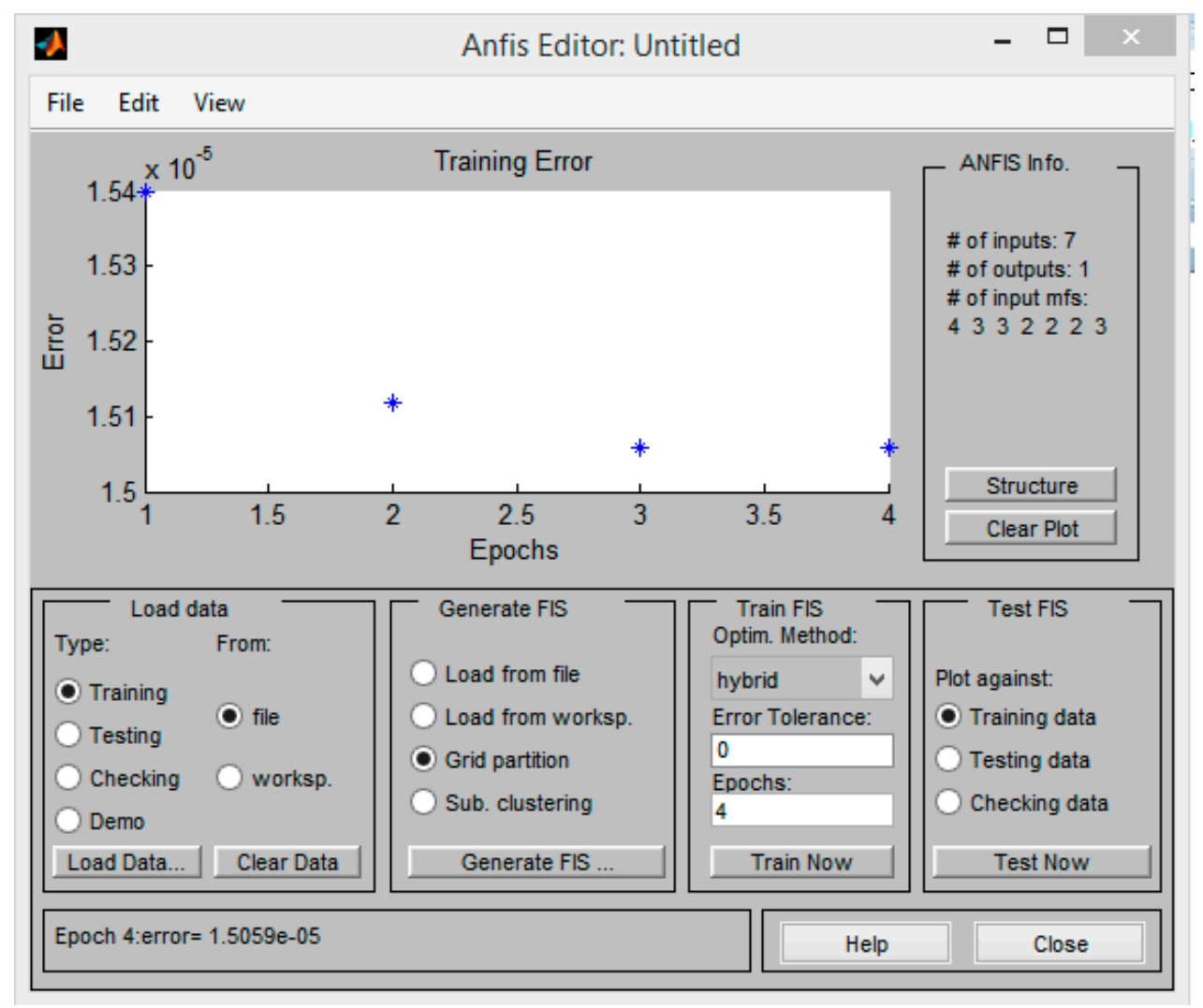

Figure 14. Training error at 4 epochs.

\section{Results}

After the development of these models by using the fuzzy and neuro-fuzzy techniques, a comparative study has been done to evaluate which model is better. The performance parameters are calculated for both systems. The main evaluation for these models is to check whether the developed models are able to classify all the inputs given to the system, even if the inputs are unseen by the system or new to the system. The model, which classifies the given inputs in correct and accurate classes, is said to be the best one among the developed systems. The error or accuracy can be calculated by comparing the observed output from the system with the target output, which is given by the professional of renal cancers. If these two values are the same, then the model is said to be completely accurate. However, there is no practical model that has $100 \%$ accuracy for the classification.

\subsection{Calculation of Performance Parameters for Fuzzy Expert System}

Fifty different tests have been carried out to examine the expert system for renal cancer closely. The result displayed by the multi-layered fuzzy expert system is compared with the result given by the physician. By contrasting these tests, it is noticed that out of 50 test cases, 48 test cases are classified into the correct and exact class.

The confusion matrix for the fold 1 of these test cases is drawn in Table 8. In this table, there are four column of class names with their test cases. For example, in the column 1, 15 cases of minor class have been classified correctly in the minor class. Similarly, in column 2, there are 13 cases of moderate 
class, but 12 test cases are classified into moderate class, 1 test case is classified into the false class i.e., in serious class. Similarly, Tables 9-11 show the confusion matrix for the fold 2, fold 3 and fold 4 respectively.

Table 8. Confusion Matrix for fold 1.

\begin{tabular}{ccccc}
\hline Minor & Moderate & Serious & Critical & Class Name \\
\hline 15 & 00 & 00 & 00 & Minor \\
\hline 00 & 12 & 01 & 00 & Moderate \\
\hline 00 & 00 & 10 & 00 & Serious \\
\hline 01 & 00 & 00 & 11 & Critical \\
\hline
\end{tabular}

Table 9. Confusion Matrix for fold 2.

\begin{tabular}{ccccc}
\hline Minor & Moderate & Serious & Critical & Class Name \\
\hline 15 & 00 & 00 & 00 & Minor \\
\hline 01 & 12 & 00 & 00 & Moderate \\
\hline 00 & 00 & 09 & 01 & Serious \\
\hline 01 & 00 & 00 & 11 & Critical \\
\hline
\end{tabular}

Table 10. Confusion Matrix for fold 3.

\begin{tabular}{ccccc}
\hline Minor & Moderate & Serious & Critical & Class Name \\
\hline 14 & 01 & 00 & 00 & Minor \\
\hline 00 & 12 & 01 & 00 & Moderate \\
\hline 00 & 00 & 10 & 00 & Serious \\
\hline 00 & 00 & 00 & 12 & Critical \\
\hline
\end{tabular}

Table 11. Confusion Matrix for fold 4.

\begin{tabular}{ccccc}
\hline Minor & Moderate & Serious & Critical & Class Name \\
\hline 15 & 00 & 00 & 00 & Minor \\
\hline 00 & 12 & 01 & 00 & Moderate \\
\hline 00 & 01 & 09 & 00 & Serious \\
\hline 00 & 00 & 00 & 12 & Critical \\
\hline
\end{tabular}

Now, these confusion matrixes have been reduced on the basis of its dimensionality. Tables 12-15 show the reduced confusion matrix for every fold by considering first two columns of Tables 8-11 as "No" and rest of the columns are taken as "Yes".

Table 12. Matrix with reduced dimensions for fold 1 .

\begin{tabular}{ccc}
\hline No & Yes & Class Name \\
\hline 27 & 01 & No \\
\hline 01 & 21 & Yes \\
\hline
\end{tabular}


Table 13. Matrix with reduced dimensions for fold 2.

\begin{tabular}{ccc}
\hline No & Yes & Class Name \\
\hline 27 & 02 & No \\
\hline 01 & 20 & Yes \\
\hline
\end{tabular}

Table 14. Matrix with reduced dimensions for fold 3.

\begin{tabular}{ccc}
\hline No & Yes & Class Name \\
\hline 26 & 00 & No \\
\hline 01 & 22 & Yes \\
\hline
\end{tabular}

Table 15. Matrix with reduced dimensions for fold 4.

\begin{tabular}{ccc}
\hline No & Yes & Class Name \\
\hline 27 & 01 & No \\
\hline 01 & 21 & Yes \\
\hline
\end{tabular}

From Table 12, the values of true positive, false negative, false positive and true negative can be evaluated as 21, 01, 01 and 27 respectively, and similarly, these values are carried out from Tables 13-15. Table 16 describes the average value of performance parameters calculated for the four folds of $k$-fold cross validation.

Table 16. Calculated performance parameters for fuzzy inference system.

\begin{tabular}{cccccc}
\hline Parameters & Fold 1 & Fold 2 & Fold 3 & Fold 4 & Overall \\
\hline Sensitivity or True Positive rate $=\frac{(T P)}{(T P+F N)}$ & $95.45 \%$ & $95.23 \%$ & $95.65 \%$ & $95.45 \%$ & $95.44 \%$ \\
\hline Specificity $=\frac{(T N)}{(T N+F P)}$ & $96.42 \%$ & $93.10 \%$ & $100 \%$ & $96.42 \%$ & $96.48 \%$ \\
\hline Precision $=\frac{(T P)}{(T P+F P)}$ & $95.45 \%$ & $90.90 \%$ & $100 \%$ & $95.45 \%$ & $95.45 \%$ \\
\hline Classification Accuracy $=\frac{(T P+T N)}{(T P+F P+T N+F N)}$ & $96 \%$ & $94 \%$ & $98 \%$ & $96 \%$ & $96 \%$ \\
\hline
\end{tabular}

\subsection{Calculation of Performance Parameters for ANFIS}

The confusion matrixes for each fold, for the adaptive neuro-fuzzy inference system for renal cancer, are shown in Tables 17-20. In these tables, the number of test cases, which are classified correctly as well as the test cases which are classified into the incorrect class are described.

Table 17. Confusion Matrix for fold 1.

\begin{tabular}{ccccc}
\hline Minor & Moderate & Serious & Critical & Class Name \\
\hline 15 & 00 & 00 & 00 & Minor \\
\hline 00 & 13 & 01 & 00 & Moderate \\
\hline 00 & 00 & 10 & 00 & Serious \\
\hline 00 & 00 & 00 & 11 & Critical \\
\hline
\end{tabular}


Table 18. Confusion Matrix for fold 2.

\begin{tabular}{ccccc}
\hline Minor & Moderate & Serious & Critical & Class Name \\
\hline 15 & 00 & 00 & 00 & Minor \\
\hline 00 & 13 & 01 & 00 & Moderate \\
\hline 00 & 00 & 10 & 00 & Serious \\
\hline 01 & 00 & 00 & 10 & Critical \\
\hline
\end{tabular}

Table 19. Confusion Matrix for fold 3.

\begin{tabular}{ccccc}
\hline Minor & Moderate & Serious & Critical & Class Name \\
\hline 15 & 00 & 00 & 00 & Minor \\
\hline 00 & 14 & 00 & 00 & Moderate \\
\hline 00 & 00 & 10 & 00 & Serious \\
\hline 00 & 00 & 00 & 11 & Critical \\
\hline
\end{tabular}

Table 20. Confusion Matrix for fold 4.

\begin{tabular}{ccccc}
\hline Minor & Moderate & Serious & Critical & Class Name \\
\hline 15 & 00 & 00 & 00 & Minor \\
\hline 00 & 13 & 01 & 00 & Moderate \\
\hline 00 & 01 & 09 & 00 & Serious \\
\hline 00 & 00 & 00 & 11 & Critical \\
\hline
\end{tabular}

The confusion matrixes with the reduced dimensionality are shown in Tables 21-24. In these tables, the first two columns of Tables 17-20 are merged together and considered as "No", and the last two columns are merged together and taken as "Yes".

Table 21. Matrix with reduced dimensions for fold 1.

\begin{tabular}{ccc}
\hline No & Yes & Class Name \\
\hline 28 & 01 & No \\
\hline 00 & 21 & Yes \\
\hline
\end{tabular}

Table 22. Matrix with reduced dimensions for fold 2.

\begin{tabular}{ccc}
\hline No & Yes & Class Name \\
\hline 28 & 01 & No \\
\hline 01 & 20 & Yes \\
\hline
\end{tabular}

Table 23. Matrix with reduced dimensions for fold 3.

\begin{tabular}{ccc}
\hline No & Yes & Class Name \\
\hline 29 & 00 & No \\
\hline 00 & 21 & Yes \\
\hline
\end{tabular}


Table 24. Matrix with reduced dimensions for fold 4 .

\begin{tabular}{ccc}
\hline No & Yes & Class Name \\
\hline 29 & 00 & No \\
\hline 01 & 20 & Yes \\
\hline
\end{tabular}

From Table 21, the values of true positive, false negative, false positive and true negative can be evaluated as $21,00,01$ and 28, respectively. Similarly, these values are carried out from Tables 22-24. Table 25 describes the average value of performance parameters calculated for the four folds of $k$-fold cross validation.

Table 25. Calculated performance parameters for ANFIS.

\begin{tabular}{cccccc}
\hline Parameters & Fold 1 & Fold 2 & Fold 3 & Fold 4 & Overall \\
\hline Sensitivity $=\frac{(T P)}{(T P+F N)}$ & $100 \%$ & $95.23 \%$ & $100 \%$ & $95.23 \%$ & $97.61 \%$ \\
\hline Specificity $=\frac{(T N)}{(T N+F P)}$ & $96.55 \%$ & $96.55 \%$ & $100 \%$ & $100 \%$ & $98.27 \%$ \\
\hline Precision $=\frac{(T P)}{(T P+F P)}$ & $95.45 \%$ & $95.23 \%$ & $100 \%$ & $100 \%$ & $97.67 \%$ \\
\hline Classification Accuracy $=\frac{(T P+T N)}{(T P+F P+T N+F N)}$ & $98 \%$ & $96 \%$ & $100 \%$ & $98 \%$ & $98 \%$ \\
\hline
\end{tabular}

Nikita et al. [27] proposed an inference system for the detection of renal cancer by using the adaptive neuro-fuzzy technique. The dataset in the numeric form is provided to the system for training and testing. The triangular membership functions are used for developing the medical inference system. The accuracy, sensitivity, specificity and precision parameters are calculated for the performance evaluation of the system. The system achieved $96 \%, 95.5 \%, 96.1 \%$ and $95.8 \%$ accuracy, sensitivity, specificity and precision, respectively.

After comparing the performances of Nikita et al. [27] with the proposed system, it is observed that the adaptive neuro-fuzzy inference system developed in this research work is better than the existing system. Hence, the ANFIS is more accurate than FIS. The performance of both developed systems is shown in Table 26.

Table 26. Calculated parameters from the developed systems.

\begin{tabular}{ccccc}
\hline Models/Parameters & Classification Accuracy & Sensitivity & Specificity & Precision \\
\hline Fuzzy & $96 \%$ & $95.44 \%$ & $96.48 \%$ & $95.45 \%$ \\
\hline ANFIS & $98 \%$ & $97.61 \%$ & $98.27 \%$ & $97.67 \%$ \\
\hline
\end{tabular}

The calculated estimation of both proposed systems is also represented by using a bar chart. In the bar chart, the two axes are there. One is the $X$-axis which is horizontal, and it will represent the proposed models that are fuzzy and ANFIS. Another axis is the $Y$-axis which is vertical and presents the percentages. The bar height views the obtained percentage of performance parameters of models. Figure 15 depicts a bar chart for the comparison of two models.

From the bar chart, it is evaluated that an intelligent medical diagnostic system for renal cancer using the adaptive neuro-fuzzy inference system is more accurate, and precise as compared to the fuzzy inference system for the detection of patients suffering from renal cancer. 


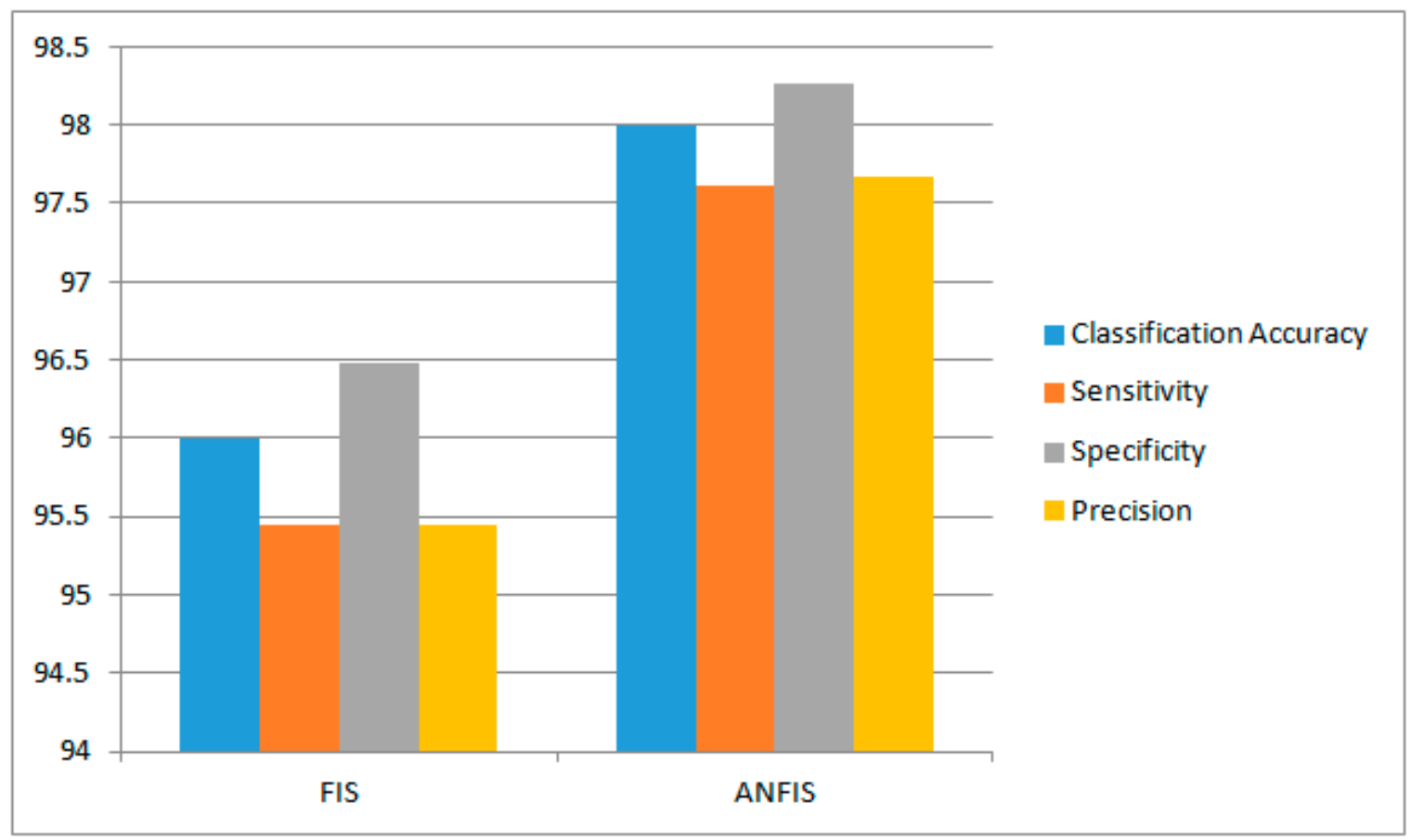

Figure 15. Bar chart for comparison of FIS and ANFIS.

\section{Conclusions}

The proposed intelligent system using neuro-fuzzy helps the fresher doctors for the detection of renal cancer. It is helpful for those physicians who do not have much experience to detect renal cancer and to evaluate its stage. Hence, this system has the capability to act as a training and supporting tool for doctors. It can be used in those areas where the resources are not equivalent to requirements. The various parameters are calculated to find the performance of the proposed systems. These parameters are precision, classification accuracy, sensitivity and specificity. According to the comparison study on the performance of both models, the medical intelligent system using the neuro-fuzzy technique is more suitable, accurate and precise. A computer system with MATLAB software is the only requirement to implement this proposed work.

The developed systems for the diagnosis of renal cancer is more accurate than other used methods as the fuzzy logic can deal with the imprecise data, as all technologies used in related work deal with a crisp dataset. The system can also work with the dataset that contains missing values of test cases. The fuzzy logic has the limitation that it cannot train the system from the examples and is not capable of adapting itself according to the environment or by considering the new unseen data. This limitation of fuzzy logic has been overcome by merging it with the neural network and making a hybrid system known as Adaptive Neuro-Fuzzy Inference System (ANFIS).

For future work in the detection of renal cancer, researchers can take more performance parameters for the evaluation. The input variables or risk factors can also be enhanced for accurate classification and to obtain a correct result for the diagnosis of renal cancer.

Author Contributions: Investigation, J.S.; Methodology, N.J., J.S., B.K., H.S., D.P., S.J., C.S. and G.P.J.; Project administration, B.K., H.S., D.P., S.J., C.S. and G.P.J.; Resources, B.K., H.S., D.P., C.S. and G.P.J.; Software, N.J.; Validation, B.K., H.S., S.J., C.S. and G.P.J.; Visualization, N.J.; Writing-original draft, H.S., D.P., S.J., C.S. and G.P.J.; Writing—review and editing, B.K., H.S., D.P., S.J., C.S. and G.P.J. All authors have read and agreed to the published version of the manuscript.

Funding: This work was supported by Institute of Information \& Communications Technology Planning \& Evaluation (IITP) grant funded by the Korean government (MSIT) (No.2017-0-01714).

Conflicts of Interest: The authors declare no conflict of interest. 


\section{References}

1. Golodetz, S.; Voiculescu, I.; Cameron, S. A Proposed Decision-Support System for (Renal) Cancer Imaging. In Proceedings of the 2007 Frontiers in the Convergence of Bioscience and Information Technologies, Jeju Island, Korea, 11-13 October 2007; pp. 361-366.

2. Linguraru, M.; Wang, S.; Shah, F.; Gautam, R.; Peterson, J.; Linehan, W.; Summers, R. Computer-aided renal cancer quantification and classification from contrast contrast-enhanced $\mathrm{CT}$ via histograms of curvature curvature-related features elated. In Proceedings of the 31st Annual International Conference of the IEEE Engineering in Medicine and Biology Society: Engineering the Future of Biomedicine, Minneapolis, MN, USA, 2-6 Septempber 2009; pp. 6679-6682.

3. Strawn, N.; Yao, J. Tracking kidney tumor dimensional measurements via image morphing. In Proceedings of the International Conference on Image Processing, ICIP, Hongkong, China, 26-29 September 2010; pp. 1721-1724.

4. Abhilash, R.H.; Chauhan, S. Respiration-induced movement correlation for synchronous noninvasive renal cancer surgery. IEEE Trans. Ultrason. Ferroelectr. Freq. Control 2012, 59, 1478-1486. [CrossRef] [PubMed]

5. Schwartz, M.; Park, M.; Phan, J.H.; Wang, M.D. Integration of multimodal RNA-seq data for prediction of kidney cancer survival. In Proceedings of the 2015 IEEE International Conference on Bioinformatics and Biomedicine, BIBM 2015, Washington, DC, USA, 9-12 November 2015; pp. 1591-1595.

6. Tander, B.; Özmen, A.; Özden, E. Neural network design for the recurrence prediction of post-operative non-metastatic kidney cancer patients. In Proceedings of the ELECO 2015-9th International Conference on Electrical and Electronics Engineering, Bursa, Turkey, 26-28 November 2016; pp. 162-165.

7. Vasilescu, G.M.; Cauni, V.; Kacso, G.; Stănculescu, M.; Marin, M.E.; Maricaru, M.; Hănţilă, I.F. Issues on early cancer detection using thermographic methods. In Proceedings of the 2017 10th International Symposium on Advanced Topics in Electrical Engineering, Bucharest, Romania, 23-25 March 2017; pp. 283-286.

8. Jones, J.M.; Bhatt, J.; Avery, J.; Laupacis, A.; Cowan, K.; Basappa, N.S.; Basiuk, J.; Canil, C.; Al-Asaaed, S.; Heng, D.Y.C.; et al. Setting Research Priorities for Kidney Cancer. Eur. Urol. 2017, 72, 861-864. [CrossRef] [PubMed]

9. Li, Y.; Hu, L.; Xia, Q.; Yuan, Y.; Mi, Y. The impact of metformin use on survival in kidney cancer patients with diabetes: A meta-analysis. Int. Urol. Nephrol. 2017, 49, 975-981. [CrossRef] [PubMed]

10. Deng, S.P.; Cao, S.; Huang, D.S.; Wang, Y.P. Identifying Stages of Kidney Renal Cell Carcinoma by Combining Gene Expression and DNA Methylation Data. IEEE/ACM Trans. Comput. Biol. Bioinform. 2017, 14, 1147-1153. [CrossRef] [PubMed]

11. Que, W.C.; Qiu, H.Q.; Cheng, Y.; Liu, M.B.; Wu, C.Y. PTEN in kidney cancer: A review and meta-analysis. Clin. Chim. Acta 2018, 480, 92-98. [CrossRef] [PubMed]

12. Tuncer, S.A.; Alkan, A. A decision support system for detection of the renal cell cancer in the kidney. Meas. J. Int. Meas. Confed. 2018, 123, 298-303. [CrossRef]

13. Aljouie, A.; Roshan, U.; Patel, N. Cross-validation and cross-study validation of kidney cancer with machine learning and whole exome sequences from the National Cancer Institute. In Proceedings of the 2018 IEEE Conference on Computational Intelligence in Bioinformatics and Computational Biology, CIBCB 2018, Saint Louis, MI, USA, 23-25 August 2018; pp. 1-6.

14. Szymańska, K. Kidney Cancer: Diagnosis and Treatment. In Encyclopedia of Cancer (Third Edition); Boffetta, P., Hainaut, P., Eds.; Academic Press: Oxford, UK, 2019; ISBN 978-0-12-812485-7.

15. Nagisetty, I. Integration of Neural Networks and Fuzzy Systems. In Soft Computing: Techniques and its Applications in Electrical Engineering; Studies in Computational Intelligence; Springer: Berlin, Germany, 2008; Volume 103, pp. 479-499. ISBN 978-3-540-77480-8.

16. Jang, J.S.R. ANFIS: Adaptive-Network-Based Fuzzy Inference System. IEEE Trans. Syst. Man Cybern. 1993, 23, 665-685. [CrossRef]

17. Polat, K.; Güneş, S. An expert system approach based on principal component analysis and adaptive neuro-fuzzy inference system to diagnosis of diabetes disease. Digit. Signal Process. A Rev. J. 2007, 17, 702-710. [CrossRef]

18. Yuan, Y.; Suarga, S. On the integration of neural networks and fuzzy logic systems. In Proceedings of the IEEE International Conference on Systems, Man and Cybernetics, Torino, Italy, 26-30 June 1995; Volume 1, pp. 452-457. 
19. Singla, J. Intelligent Medical Diagnostic System for Diabetes. In Hidden Link Prediction in Stochastic Social Networks; Premier Reference Source; IGI Global: Hershey, PA, USA, 2019; Volume 2019, pp. 188-209, ISBN 978-1-5225-9096-5.

20. Saribudak, Y.D.; Gundry, S.; Hsieh, J.; Uyar, M.U. Mathematical models of tumor growth using Voronoi tessellations in pathology slides of kidney cancer. In Proceedings of the 37th Annual International Conference of the IEEE Engineering in Medicine and Biology Society (EMBC), Milan, Italy, 25-29 August 2015; pp. 4454-4457.

21. Faisal, T.; Taib, M.N.; Ibrahim, F. Adaptive Neuro-Fuzzy Inference System for diagnosis risk in dengue patients. Expert Syst. Appl. 2012, 39, 4483-4495. [CrossRef]

22. Marashi, M.; Torkashvand, A.M.; Ahmadi, A.; Esfandyari, M. Adaptive neuro-fuzzy inference system: Estimation of soil aggregates stability. Acta Ecol. Sin. 2019, 39, 95-101. [CrossRef]

23. Sivathasan, S.; Cecelja, F.; Balachandran, W. ECG diagnosis using neural network and fuzzy expert system. In Proceedings of the IEEE Instrumentation and Measurement Technology Conference, Baltimore, MD, USA, 1-4 May 2000; Volume 2, pp. 988-992.

24. Ananthi, S.; Bhuvaneswari, V. Prediction of heart and kidney risks in diabetic prone population using fuzzy classification. In Proceedings of the 2017 International Conference on Computer Communication and Informatics, ICCCI 2017, Coimbatore, India, 5-7 January 2017.

25. Meza-palacios, R.; Aguilar-lasserre, A.A.; Ureña-bogarín, E.L.; Vázquez-rodríguez, C.F.; Posada-Gómez, R.; Trujillo-Mata, A. Development of a fuzzy expert system for the nephropathy control assessment in patients with type 2 diabetes mellitus. Expert Syst. Appl. 2017, 72, 335-343. [CrossRef]

26. Mdzinarishvili, T.; Gleason, M.X.; Sherman, S. Influence of Time Period and Birth Cohort Effects on Age-Specific Incidence Rates of Pancreatic and Kidney Cancer. In Proceedings of the 2010 43rd Hawaii International Conference on System Sciences, Honolulu, HI, USA, 5-8 January 2010; pp. 1-9.

27. Nikita; Kaur, B.; Sadawarti, D.H.; Singla, D.J. A Neuro-Fuzzy Based Intelligent System for Diagnosis of Renal Cancer. Int. J. Sci. Technol. 2020, 9, 3699-3705.

(C) 2020 by the authors. Licensee MDPI, Basel, Switzerland. This article is an open access article distributed under the terms and conditions of the Creative Commons Attribution (CC BY) license (http://creativecommons.org/licenses/by/4.0/). 